\title{
Introduction
}

Nutrition\& Metabolism

\section{Long-Term Health Impact of Early Nutrition: The Power of Programming}

\author{
Berthold Koletzko Brigitte Brands Veit Grote Franca F. Kirchberg \\ Christine Prell Peter Rzehak Olaf Uhl Martina Weber \\ for the Early Nutrition Programming Project
}

Division of Metabolic and Nutritional Medicine, Ludwig-Maximilians-Universität Munich, Dr. von Hauner Children's

Hospital, University of Munich Medical Center, Munich, Germany

\section{Keywords}

Early nutrition · Pregnancy · Infant nutrition · Metabolic programming $\cdot$ Developmental origins of health and disease - Obesity · Adiposity

\begin{abstract}
The Power of Programming conference 2016 at LudwigMaximilians-Universität Munich brought together about 600 researchers and other stakeholders from around the world who reviewed the recent evidence on the lasting health impact of environment and nutrition during early life, from pre-pregnancy to early childhood. The conference was hosted by the Early Nutrition Project, a multidisciplinary research collaboration funded by the European Commission with collaborating researchers from 35 institutions in 15 countries in Europe, the United States and Australia. The project explores the early origins of obesity, adiposity and associated non-communicable diseases, underlying mechanisms and opportunities for prevention. The project also proactively supports translational application of research findings. In fact, some existing evidence has already been rapidly adopted into policy, regulatory standards and practice. Further, broad dissemination of findings is achieved through the established digital eLearning platform of the Early Nutrition eAcademy, video clip-based learning and
\end{abstract}

() 2017 S. Karger AG, Basel graphically supported messaging to consumers. The project demonstrated powerful effects of early metabolic programming on later health. Compared to other common prevention strategies, modifying risk trajectories in early life can achieve a much larger risk reduction and be more cost-effective. While some effective prevention strategies have been promptly implemented in policy and guidelines, legislation and practice, in other areas, the uptake is limited by a paucity of quality human intervention trials and insufficient evaluation of the feasibility of implementation and econometric impact. This needs to be strengthened by future collaborative research work.

(c) 2017 S. Karger AG, Basel

\section{The Power of Programming Conference 2016}

This issue of the Annals of Nutrition and Metabolism presents manuscripts based on presentations at the international conference "The Power of Programming conference 2016" held at Ludwig-Maximilians-Universität $\mathrm{Mu}$ nich, Germany in October 2016. The conference was truly global with attendance by about 600 participants from 49 countries on all 5 continents. Delegates comprised scientists from a variety of disciplines; health care professionals; experts in public health, policy and regulatory af-

\section{KARGER}

E-Mail karger@karger.com

www.karger.com/anm
Berthold Koletzko, Professor of Paediatrics

Division of Metabolic and Nutritional Medicine

Ludwig-Maximilians-Universität Munich, Dr. von Hauner Children's Hospital

Lindwurmstrasse 4, DE-80337 Munich (Germany)

E-Mail office.koletzko@med.uni-muenchen.de 
fairs; and representatives of commercial companies related to biomedical, dietetic and food products, as well as consumer, patient and parent groups. The conference programme was built around the theme of long-term programming effects of early nutrition and lifestyle before and during pregnancy, in infancy and in early childhood, on later health and disease risk. New information was shared in 97 lectures and 132 poster presentations. While a broad spectrum of long-term health effects was addressed, particular attention was directed to programming effects on later obesity, adiposity (body fatness), and related non-communicable disorders such as insulin resistance, diabetes and other metabolic disorders, cardiovascular diseases such as stroke and ischaemic heat disease, asthma and some forms of cancer. In addition, 6 workshops were held including a "New Investigators Forum," a workshop on the eLearning platform "Early Nutrition eAcademy" and a workshop with information on the EC-funded project DynaHEALTH. During the discussions, a strong focus was directed to the potential of translational application of research results and wider dissemination to achieve a broad impact of scientific progress, as well as defining future research opportunities. The scientific quality of the conference was rated as good by $47 \%$ of delegates and as excellent by $53 \%$.

\section{The Early Nutrition Project}

This Power of Programming conference was hosted by the Early Nutrition Project, a multinational, multidisciplinary research collaboration that receives funding from the European Commission's Framework 7 Programme (http://www.project-earlynutrition.eu; FP7289346-EARLY NUTRITION) and co-funding from the Australian National Health and Medical Research Council for the funding period 2012-2017. With a total budget of 11.1 million Euro and collaborating researchers from 35 institutions in 15 countries in Europe, the United States of America and Australia (Table 1), the Early Nutrition Project coordinated at Dr. von Hauner Children's Hospital, Ludwig-Maximilians-Universität Munich, is the largest research project worldwide on developmental origins of health [1]. The project objectives are focussed on exploring the early origins of obesity, adiposity and associated noncommunicable diseases (NCDs), underlying mechanisms and opportunities for preventive interventions. This focus has been prioritized because of the strong evidence of developmental programming of NCDs as well as their very high and further increasing disease burden [2-6], includ-
Table 1. Partner institutions participating in the Early Nutrition Project

\begin{tabular}{|c|c|}
\hline European academic partners & Country \\
\hline LMU Muenchen & Germany \\
\hline Kings College London & UK \\
\hline Medical University of Graz & Austria \\
\hline Statens Serum Institute & Denmark \\
\hline University of Murcia & Spain \\
\hline University of Nottingham & UK \\
\hline Norwegian Institute of Public Health & Norway \\
\hline University College Dublin & Ireland \\
\hline University Amsterdam & The Netherlands \\
\hline University Rovira I Virgili & Spain \\
\hline Leiden University Medical Center & The Netherlands \\
\hline University of Southampton & UK \\
\hline Erasmus University Medical Center & The Netherlands \\
\hline University of Granada & Spain \\
\hline University of Copenhagen & Denmark \\
\hline Medical University of Warsaw & Poland \\
\hline University of Cambridge & UK \\
\hline University College Cork & Ireland \\
\hline University Degli Studi di Milano & Italy \\
\hline The Children's Memorial Health Institute & Poland \\
\hline National and Kapodistrian University of Athens & Greece \\
\hline Centre hospitalier chrétien, Liège & Belgium \\
\hline \multicolumn{2}{|l|}{ Small and medium enterprises } \\
\hline Medscinet $\mathrm{AB}$ & Sweden \\
\hline ServiceXS BV & The Netherlands \\
\hline Biolution GmbH & Austria \\
\hline \multicolumn{2}{|l|}{ Industry Partners } \\
\hline Danone Research BV & The Netherlands \\
\hline Beneo GmbH & Germany \\
\hline Abbott Nutrition Research & Spain \\
\hline \multicolumn{2}{|l|}{ Partners in the USA } \\
\hline University of California & California, USA \\
\hline Harvard Medical School, Boston & MA, USA \\
\hline University of Texas Health Sciences Center & Texas, USA \\
\hline $\begin{array}{l}\text { The MetroHealth System, Case Western } \\
\text { Reserve University School of Medicine } \\
\text { Partners in Australia }\end{array}$ & Cleveland, USA \\
\hline $\begin{array}{l}\text { Telethon Institute for Child Health Research, } \\
\text { University of Western Australia }\end{array}$ & $\begin{array}{l}\text { Western Australia, } \\
\text { Australia }\end{array}$ \\
\hline $\begin{array}{l}\text { Murdoch Children's Research Institute, } \\
\text { University of Melbourne }\end{array}$ & Victoria, Australia \\
\hline University of Adelaide & Adelaide, Australia \\
\hline
\end{tabular}

ing high losses of life years and particularly of healthylife years (Figure 1). The World Health Organisation (WHO) concluded that currently, obesity is the 5th leading cause of global deaths and responsible for $44 \%$ of the burden or diabetes mellitus, $23 \%$ of ischaemic heart disease, and $7-41 \%$ of certain cancers [7]. Since the available options for obesity treatment are far less than satisfactory, the priority in combatting the obesity epidemic is on developing and im- 


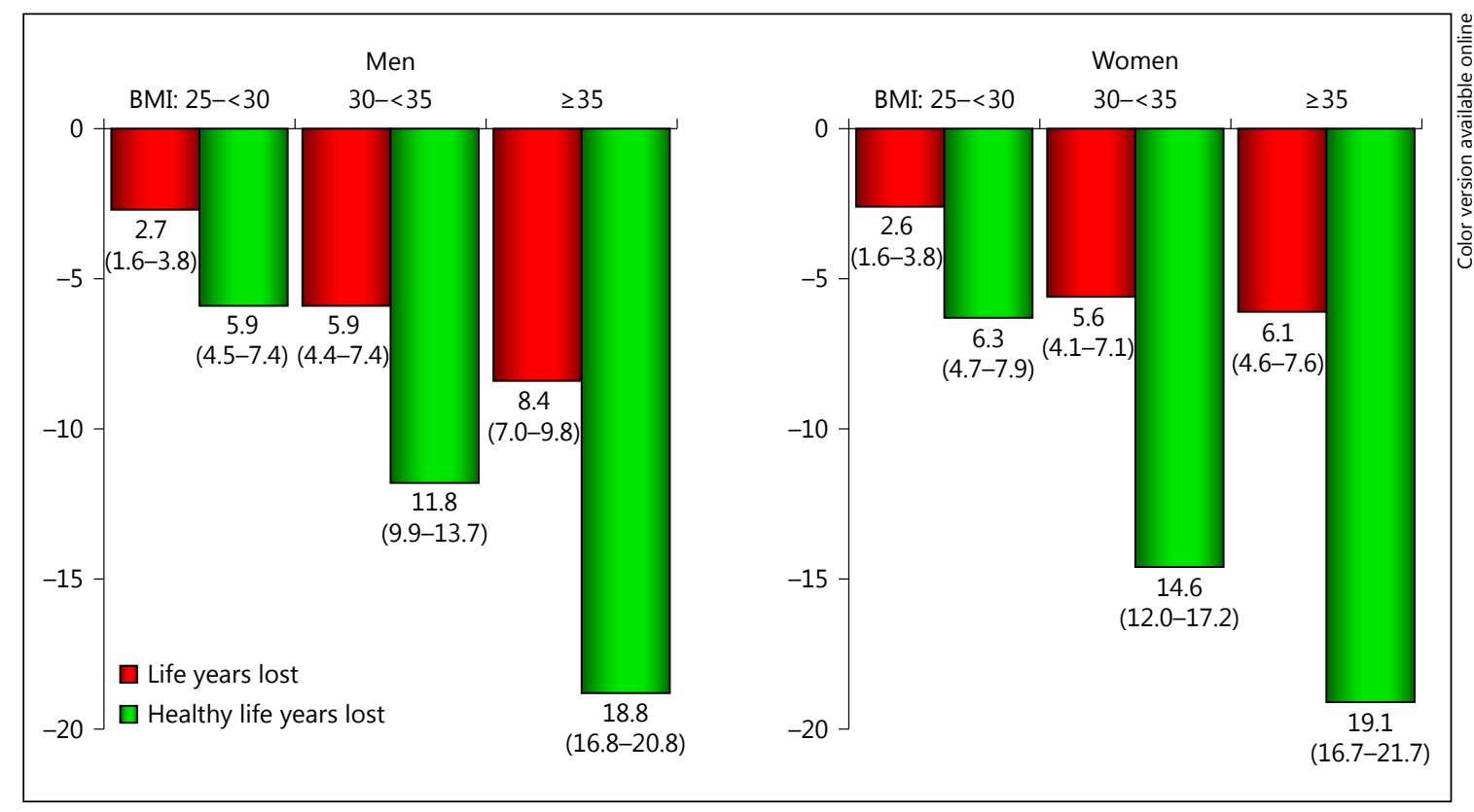

Fig. 1. The high disease burden of different degrees of overweight and obesity is apparent from the loss of life years and of disability adjusted life years (healthy life years) in affected people aged 20-39 years. Drawn from data of [5].

plementing effective and cost-effective prevention strategies. The recently published WHO report on "Ending Childhood Obesity" developed by an international scientific expert group with contributions from $100 \mathrm{WHO}$ member states concluded that particular opportunities for effective prevention of obesity and associated NCDs exist in pregnancy and pre-pregnancy, in infancy and early childhood, and in adolescence, which is considered a prepregnancy period in females [7]. This focus of the WHO report reflects the 3 key hypotheses on early life origins of adiposity and associated disorders that the workpackages of the early nutrition consortium are designed to jointly test with different and complementary methodological approaches, that is, the fuel mediated in utero hypothesis, the accelerated postnatal growth hypothesis, and the mismatch of pre- and postnatal growth trajectories hypothesis $[3,4]$ (Fig. 2). Epidemiological evidence from current prospective cohort studies describes effects and effect sizes of early environmental and nutritional exposures and develops the basis for interventions in pregnancy and early childhood, which are tested in randomized controlled trials. In addition, the project aims at characterizing underlying mechanisms for effects of programming factors acting during periods of developmental plasticity, such as endocrine, metabolic, structural and growth-modulating factors and the regulatory function of the placenta (Fig. 3).

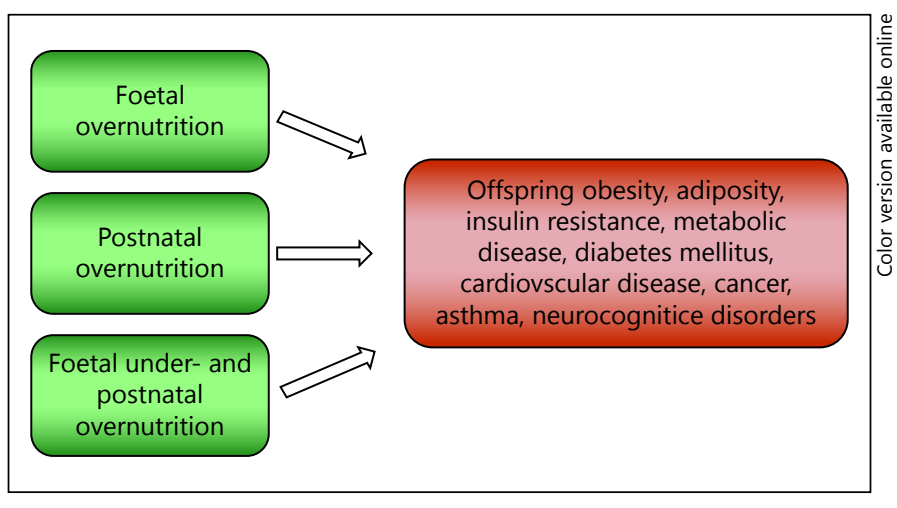

Fig. 2. The workpackages of the Early Nutrition Research Project are designed to jointly test 3 key hypotheses on early life origins of adiposity and associated disorders with different and complementary methodological approaches, that is, the fuel mediated in utero hypothesis, the accelerated postnatal growth hypothesis, and the mismatch of pre- and postnatal growth trajectories hypothesis.

The Early Nutrition Project has contributed to a better understanding of the impact of Early Nutritional Programming on health during childhood and later life. As of May 2017, a total of more than 250 scientific publications arising from the project work have been entered into the database of the project website. Early nutrition has produced better evidence for the impact of lasting ef- 


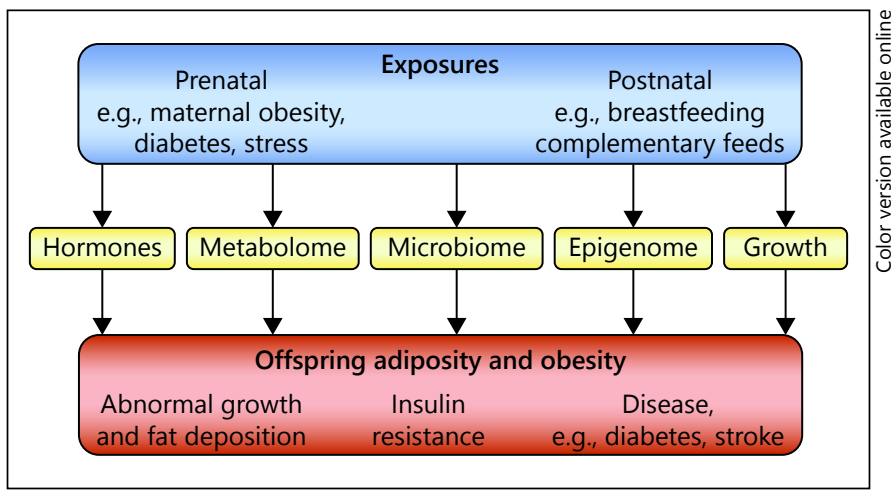

Fig. 3. Nutritional and metabolic factors acting during sensitive time periods of developmental plasticity before and after childbirth modulate cytogenesis, organogenesis, metabolic and endocrine response, and epigenetic regulation of gene expression, and thereby induce metabolic programming of lifelong health and disease risk.

Table 2. Subscapular skinfold thickness in infants aged 6 months is reduced by an antenatal lifestyle intervention in obese pregnant women to improve maternal diet (glycemic load and saturated fat intake) and physical activity (UPBEAT trial, 342 intervention, 356 control). Modified from [12]

\begin{tabular}{lll}
\hline Skinfolds & Z-score $(95 \% \mathrm{CI})$ & $p$ value \\
\hline Triceps & $-0.14(-0.38$ to 0.10$)$ & ns \\
Subscapular & $-0.26(-0.49$ to -0.02$)$ & $<0.001$ \\
\hline
\end{tabular}

ns, not significant.

fects of Early Nutrition Programming on health, well-being and performance, and the risk of obesity and associated disorders. The project has provided further clarification of the causative maternal/offspring exposures, effect sizes, key processes and mechanisms regulating programming, and on key concepts related to programming, such as the roles of accelerated foetal and/or infant growth and mismatch in the programming of obesity susceptibility. Joint evaluation of studies has been performed [8] and joint databases have been established that will facilitate further data sharing and combined individual patient data analyses. Standardization and harmonization of methodological approaches to describe key exposures and outcomes, and harmonized methodologies, for example, for assessing outcomes, sample collection and handling, analytical approaches, data management and evaluation, will improve and enhance future intervention studies and facilitate collaboration for meta-analyses and comparison of results from different studies.

\section{Translational Application of Research Results into Practice}

A key goal of the Early Nutrition Project followed from its conception was to support the transfer of indicative research findings into translational application. Here we describe just 2 examples that had a marked impact on improving practice.

Three randomized clinical trials exploring the possible impact of lifestyle modification in pregnancy on health outcomes were included in the Early Nutrition Project. The Limit trial enrolled 2,212 overweight women with a singleton pregnancy who were randomized to standard care, or to a comprehensive dietary and lifestyle intervention delivered by research staff who focussed on limiting the dietary intake of sugar and saturated fat, and on enhancing physical activity. In the intervention group, there was a non-significant trend for a lower adjusted relative risk for large for gestational age infants $(0.90,95 \%$ CI $0.77-1.07 ; p=0.24$ ), and a significant reduction in the number of infants born with a high birth weight of above $4,000 \mathrm{~g}$, which is a secondary endpoint (relative risk 0.82 , 95\% CI 0.68-0.99; $p=0.04$ ) [9]. Since birthweight $>4 \mathrm{~kg}$ predicts a doubled later obesity risk [10], this finding may be of considerable clinical relevance. The UPBEAT trial recruited 1,555 obese pregnant women and randomized them to standard care of a behavioural intervention with eight health trainer-led sessions focussing on diet and physical activity. The intervention reduced gestational weight gain but did not affect the primary outcomes, i.e. gestational diabetes in mothers and large for gestational age birth infants [11]. However, in infants followed up at the age of 6 months, subscapular skinfold thickness was found to be reduced in the intervention group, suggesting an effect of the pregnancy intervention on later infant adiposity [12] (Table 2). It appears that interventions in pregnancy alone may not be sufficient to achieve an optimal benefit, but rather programmes that need to be initiated across the early life stages from pre-pregnancy to early childhood should be explored. Also, investment in exploration of the metabolic and other predictors of fetal growth and associated health outcomes appears worthwhile to inform future focussed interventions [13].

Considerable preventive opportunity also exists with postnatal interventions. A large observational study in Germany reported that breastfeeding is associated with a sizeable risk reduction of obesity at early school age [14]. This finding was replicated in many other observational studies [15-18], which have strengthened efforts to promote, protect and support breastfeeding. We hypothe- 
Fig. 4. The dietary intakes of infants fed conventional infant formulae at the age of 3 and 6 months, expressed as percentages of intakes of breastfed infants, are slightly higher for energy [21] but markedly higher for protein [24].

Fig. 5. The Early Protein Hypothesis stipulates that a high infant protein supply in excess of metabolic requirements increases the plasma and tissue concentrations of insulinogenic amino acids, the growth mediators insulin and IGF-1, leads to enhanced infant weight gain and body fat deposition and to increased long-term risk of obesity. Modified after [19, 20].
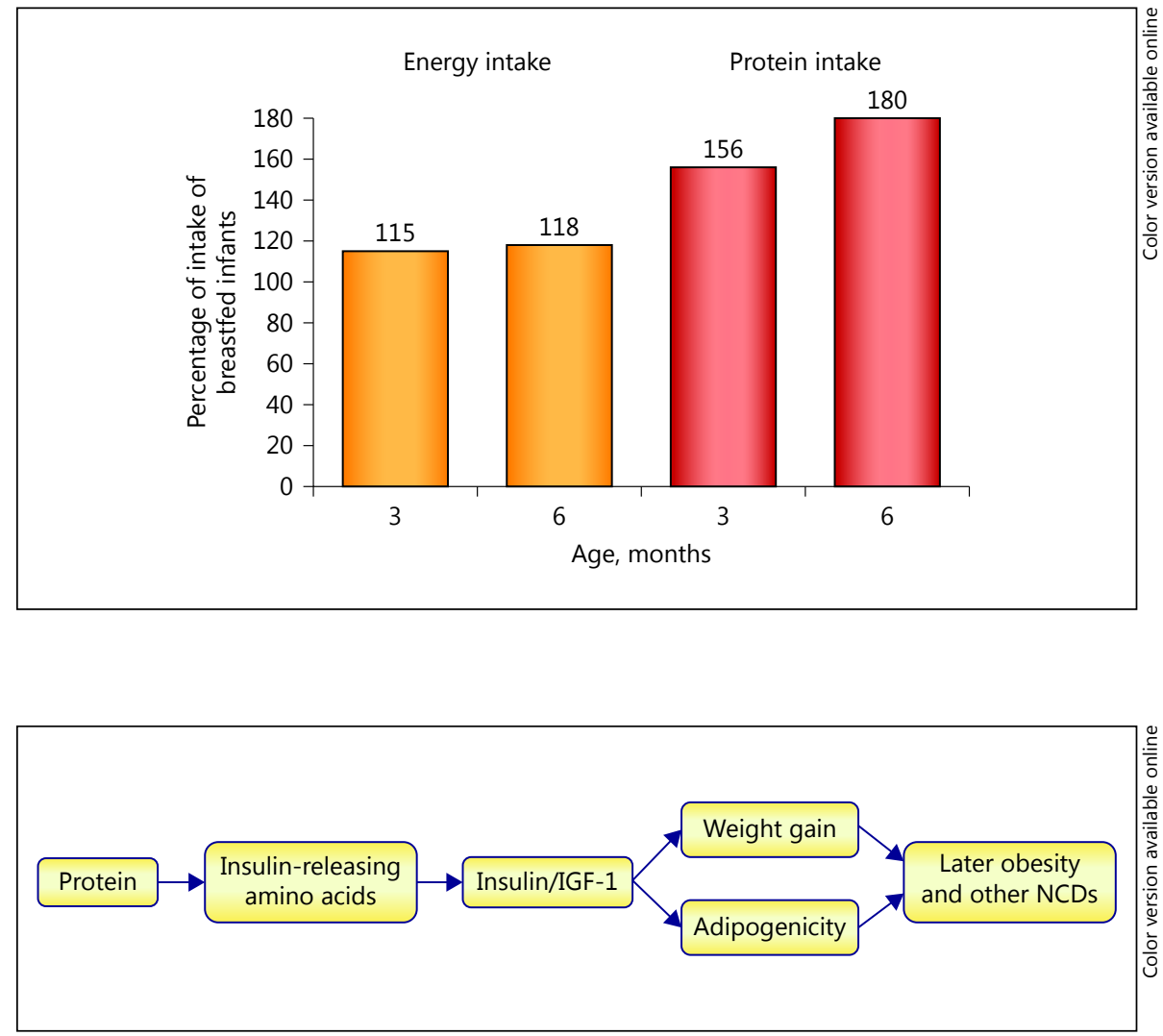

sized that the protective effect of breastfeeding might be due at least in part to a lasting programming effect of the much higher protein supply to infants fed conventional infant formula, as compared to breastfed infants, "The Early Protein Hypothesis" [19, 20]. Formula-fed infants have a slightly higher energy intake (by 15-18\%) than those breastfed (Fig. 4) [21], which is related to a higher energy cost for growth (lower energetic efficiency) in formula-fed infants $[22,23]$. In contrast to the relatively small difference in energy intake, conventional formula feeding provides $55-80 \%$ more crude protein intake, calculated on the basis of total nitrogen intake [24]. The difference in true protein supply is even greater, given that about a quarter of human milk nitrogen content is comprised of non-protein nitrogen compounds, and a significant portion of bio-functional human milk proteins resists intestinal digestion and is excreted in stools in the intact form. We considered that this marked difference in protein supply might be responsible for the programming effect of infant feeding choices on later obesity (The Early Protein Hypothesis; Fig. 5) [19, 20]. We assumed that a high protein supply at infancy that exceeds the metabolic requirements would increase plasma and tissue con- centrations of insulinogenic amino acids, the growth mediators insulin and IGF-1, and induce a higher infant weight gain and body fat deposition as well as an increased long-term risk of obesity [25]. The Early Protein Hypothesis was confirmed in a large clinical trial performed in 5 European countries, which enrolled 1,678 healthy infants born at term with a birthweight appropriate for gestational age. Infants were either fully breastfed for a minimum duration of 3 months by parental choice, or if parents chose to formula feed, they were randomized double blind at a median age of 2 weeks to feeding with conventional formula with a high protein content, or an isoenergetic intervention formula with a reduced protein content; both formulae were provided for the duration of the first year of life [26]. The lower protein supply led to a marked reduction of plasma concentrations of essential amino acids and of the secretion of insulin and IGF-1 [27-29] and to a normalization of the body mass index at the age of 2 years, as compared to the breastfed reference group [26]. Among the more than $60 \%$ of initially enrolled children in whom data on body mass index could be obtained at the age of 6 years, the obesity prevalence was $3.6 \%$ in previously breastfed children, $10.5 \%$ in chil- 


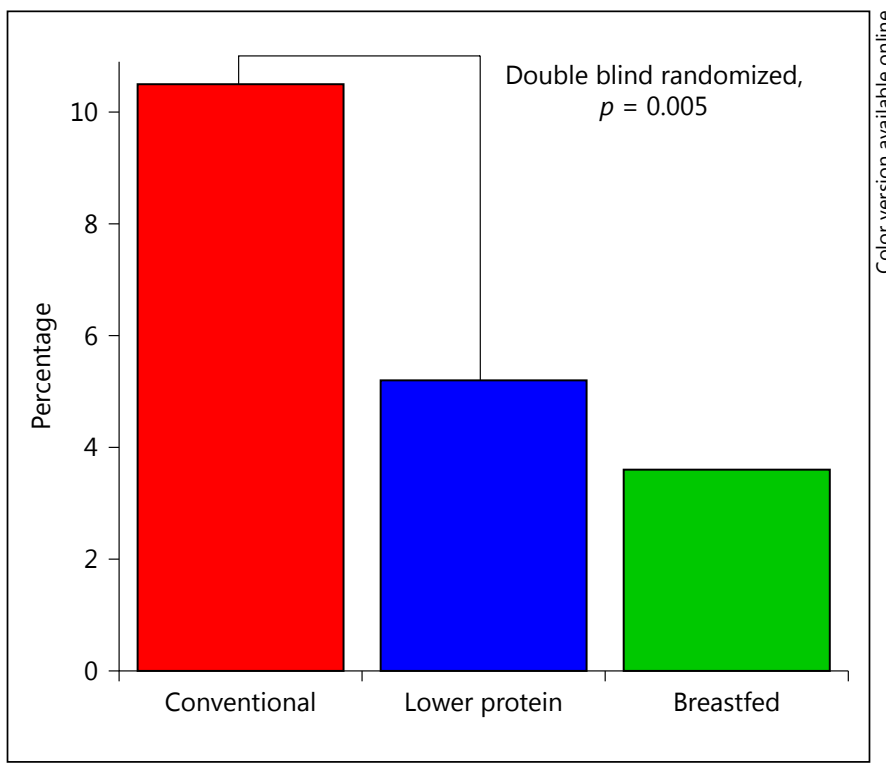

Fig. 6. The Early Protein Hypothesis was confirmed in a large trial that enrolled 1,678 healthy infants born at term who were fully breastfed for a minimum duration of 3 months or were randomized double blind to feeding for the first year of life with conventional formula with a high protein content, or were fed an isoenergetic intervention formula with reduced protein contents that were more similar to levels in human milk. At the age of 6 years, the prevalence of obesity was markedly reduced in children previously fed a lower protein formula to a level more similar to the breastfed reference group. Drawn from data of [30].

dren fed conventional infant formula, but only $5.2 \%$, and thus less than half, in children previously randomized to reduced protein formula [30] (Fig. 6). The adjusted relative obesity risk at early school age was increased 2.6 -fold by higher vs. lower protein supply in infancy $(95 \%$ CI $1.33-5.10, p=0.005)$.

These results strengthen the conclusion that the observed risk reduction for later obesity associated with breastfeeding reflects a causal effect related to the relatively low protein content of human milk. Therefore, breastfeeding should be effectively promoted, protected and supported to attenuate the later obesity risk, in addition to its numerous other benefits [31], which has now been broadly adopted in obesity prevention policies [7]. It has also become widely and rapidly accepted that infant formula used for those infants that are not or not fully breastfed should provide lower protein contents than previously used, with levels more similar to human milk contents [31]. It is very encouraging that our results have rapidly been adopted and the composition of many infant formulae marketed in Europe and globally has been changed accordingly, with a reduction of protein contents. Also, these data have led to changes in regulatory guidance in the European Union with a general acceptance of a minimum protein content of $1.8 \mathrm{~g} / 100 \mathrm{kcal}$ in infant formula, without the requirement for additional clinical evaluation, and a reduction of the permitted maximum protein content in follow-on formula [32], as well as a proposed reduction of the minimum protein content in follow-on formula to $1.8 \mathrm{~g} / 100 \mathrm{kcal}$ [33]. Also, the revision of the global standard for follow-on formula developed by the Codex Committee on Nutrition and Foods for Special Dietary Uses of the Codex Alimentarius is moving towards lowering the values for protein content [34]. In conclusion, it is very encouraging that the conclusive evidence for programming effects of infant protein supply provided by the European Union funded collaborative research has been rather rapidly adopted into policies, regulatory standards, and infant feeding practices, and hence contributes effectively to the primary prevention of obesity and its associated disorders across populations.

\section{Further Dissemination}

The Early Nutrition Project and its participating partners have effectively disseminated the project results. Project results are shared with the scientific community through publications, presentations at scientific meetings, and international workshops and congresses organized by the project. Other stakeholders have been specifically addressed with targeted communication. Evidence-based recommendations on optimized practice of nutrition before and during pregnancy, during the breast feeding period and the early life of infants, have been developed based on the project results and on systematic reviews of available evidence [35-42], in close collaboration with a broad group of stakeholders (prepared for publication). These recommendations are of considerable importance because most of the current guidance for pregnant women, particularly obese women, and for young children does not take into account the long-term programming consequences of early nutrition. We have translated these recommendations into simple messages provided through an attractive graphical format, which are shared with the broad public and specific consumer target groups to facilitate outreach (Fig. 7, 8). Project results and recommendations are also shared globally through the digital eLearning platform Early Nutrition eAcademy (www.earlynutrition.org/enea; Table 3). The CME accredited, interactive courses with self-assessments and case-based 
Fig. 7. Public communication of the Early Nutrition Project Graphical on the importance of approaching a normal body weight prior to conception. Copyright: LudwigMaximilians Universität München for the Early Nutrition Project.
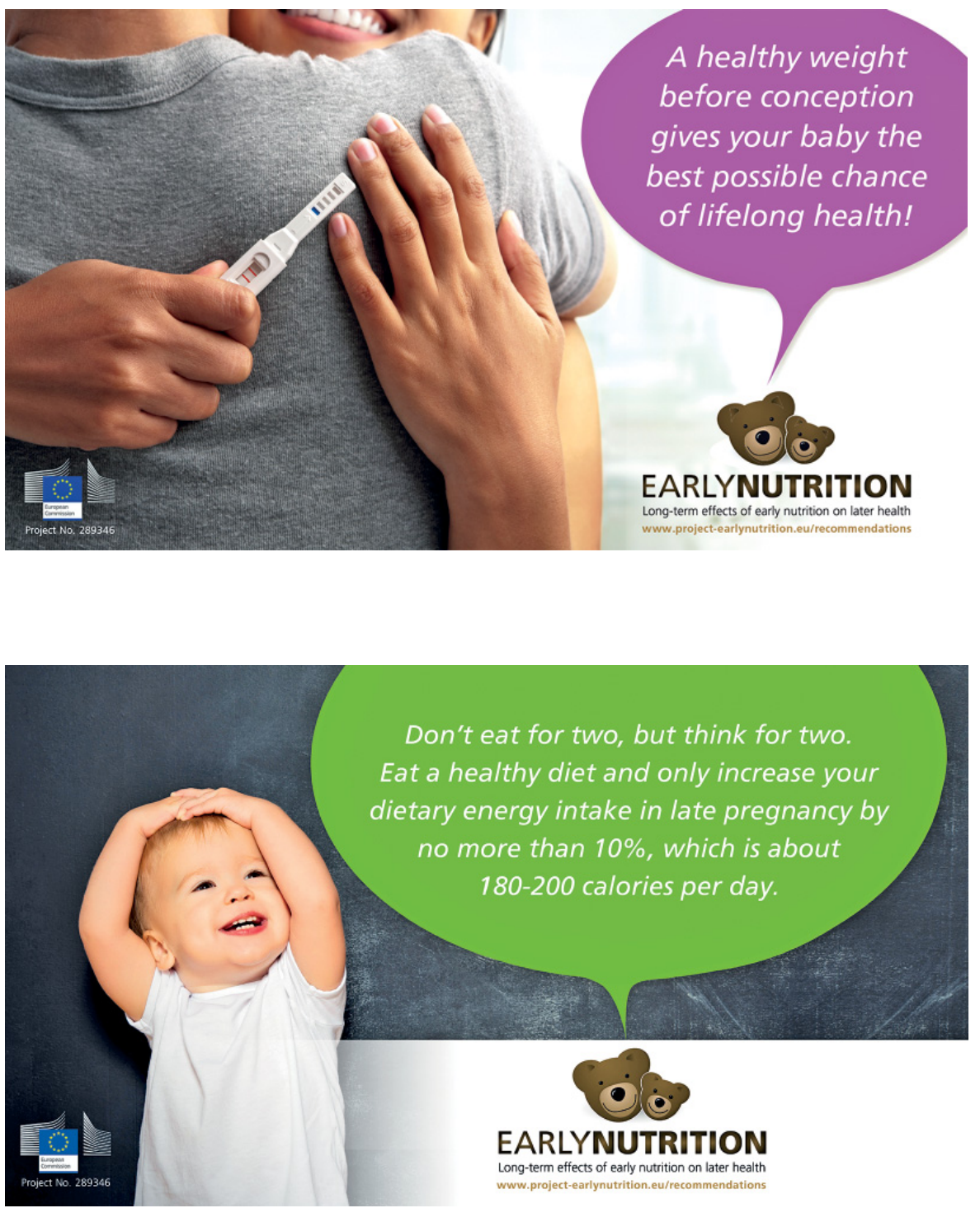

Fig. 8. Public communication of the Early Nutrition Project on the modest increase of energy needs of pregnant women. Copyright: Ludwig-Maximilians Universität München for the Early Nutrition Project. trainings are available free of charge. Many of the early nutrition partners and other global leaders in the field contribute in the Scientific Committee, as authors and reviewers. As of May 2017, more than 6,500 health care professionals from 154 countries worldwide participated in the online courses. The top 10 countries with the largest numbers of users include Germany, Mexico, the United Kingdom, Colombia, Spain, Israel, the Netherlands, Slovenia, the United States of America, and Croatia. Of interest, $22 \%$ of users are accessing the eLearning courses using mobile devices. Moreover, a video clip-based Massive Open Online Course on "Nutrition and Lifestyle in Pregnancy" has been developed, which is also accessible free of charge (www.early-nutrition.org/MOOC).
Table 3. Online courses related to Early Nutrition Programming offered by the Early Nutrition eAcademy (www.early-nutrition. org/enea; May 2017)
Core modules
Nutrition/lifestyle in pregnancy
Breastfeeding
Infant formula feeding
Complementary feeding
Focus modules
Nutritional care of preterms
Early nutrition in low-resource settings
Nutrition and epigenetics
LC-PUFAs in pregnancy, lactation and infancy
Early micronutrient supply 


\section{Conclusions}

Powerful effects of metabolic programming in early life stages on the later risk of obesity, adiposity and associated NCDs have been demonstrated. Compared to common prevention strategies applied at school age or later, modifying risk trajectories very early in life can achieve a much larger risk reduction and be more costeffective. While some effective prevention strategies have been promptly implemented in policy and guidelines, legislation, and practice, in other areas, the uptake of further early life prevention strategies into policy and practice is limited by a paucity of quality human intervention trials and insufficient evaluation of the feasibility of implementation and econometric impact, which clearly needs to be strengthened by future collaborative research work.

\section{Acknowledgements}

The authors' work is financially supported in part by the Commission of the European Communities, Projects Early Nutrition (FP7-289346), DYNAHEALTH (H2020-633595) and LIFECYCLE (H2020-SC1-2016-RTD), the European Research Council Advanced Grant META-GROWTH (ERC-2012-AdG 322605), the Erasmus Plus programme "Early Nutrition eAcademy Southeast Asia - 573651-EPP-1-2016-1-DE-EPPKA2-CBHE-JP" and the EU Interreg Programme "Focus in CD - CE111." Additional support has been received from the German Ministry of Education and Research, Berlin (grant number 01 GI 0825), the German Research Council (Ko912/12-1) and the University of Munich Innovation Initiative.

\section{Disclosure Statement}

The authors declare no conflicts of interest in relation to the content of this manuscript.

\section{References}

1 Koletzko B, Brands B, Poston L, Godfrey K, Demmelmair H; Early Nutrition Project: Early nutrition programming of long-term health. Proc Nutr Soc 2012;71:371-378.

$\checkmark 2$ Berti C, Cetin I, Agostoni C, Desoye G, Devlieger R, Emmett PM, et al: Pregnancy and infants' outcome: nutritional and metabolic implications. Crit Rev Food Sci Nutr 2016;56: 82-91.

-3 Brands B, Demmelmair H, Koletzko B; EarlyNutrition Project: How growth due to infant nutrition influences obesity and later disease risk. Acta Paediatr 2014;103:578-585.

-4 Koletzko B, Brands B, Chourdakis M, Cramer S, Grote V, Hellmuth C, et al: The Power of Programming and the EarlyNutrition Project: opportunities for health promotion by nutrition during the first thousand days of life and beyond. Ann Nutr Metab 2014;64:187-196.

5 Grover SA, Kaouache M, Rempel P, Joseph L, Dawes M, Lau DC, et al: Years of life lost and healthy life-years lost from diabetes and cardiovascular disease in overweight and obese people: a modelling study. Lancet Diabetes Endocrinol 2015;3:114-122.

6 GBD-2015-Maternal-Mortality-Collaborators: Global, regional, and national levels of maternal mortality, 1990-2015: a systematic analysis for the Global Burden of Disease Study 2015. Lancet 2016;388:1775-1812.

7 Commission-on-Ending-Childhood-Obesity: Report of the Commission on Ending Childhood Obesity. Geneva, World Health Organisation, 2016.

8 Rzehak P, Oddy WH, Mearin ML, Grote V, Mori TA, Szajewska H, et al: Infant feeding and growth trajectory patterns in childhood and body composition in young adulthood. Am J Clin Nutr 2017, in press.
9 Dodd JM, Turnbull D, McPhee AJ, Deussen AR, Grivell RM, Yelland LN, et al: Antenatal lifestyle advice for women who are overweight or obese: LIMIT randomised trial. BMJ 2014;348:g1285.

10 Yu ZB, Han SP, Zhu GZ, Zhu C, Wang XJ, Cao XG, et al: Birth weight and subsequent risk of obesity: a systematic review and metaanalysis. Obes Rev 2011;12:525-542.

-11 Poston L, Bell R, Croker H, Flynn AC, Godfrey KM, Goff L, et al: Effect of a behavioural intervention in obese pregnant women (the UPBEAT study): a multicentre, randomised controlled trial. Lancet Diabetes Endocrinol 2015;3:767-777.

12 Patel N, Godfrey KM, Pasupathy D, Levin J, Flynn AC, Hayes L, et al: Infant adiposity following a randomised controlled trial of a behavioural intervention in obese pregnancy. Int J Obes (Lond) 2017, Epub ahead of print.

13 Hellmuth C, Uhl O, Standl M, Heinrich J, Koletzko B, Thiering E: Cord blood metabolome is highly associated with birth weight, but less predictive for later weight development. Obesity Facts 2017, in press.

14 von Kries R, Koletzko B, Sauerwald T, von Mutius E, Barnert D, Grunert V, et al: Breast feeding and obesity: cross sectional study. BMJ 1999;319:147-150.

15 Arenz S, Ruckerl R, Koletzko B, von Kries R: Breast-feeding and childhood obesity - a systematic review. Int J Obes Relat Metab Disord 2004;28:1247-1256.

16 Horta BL, Victora CG: Long-Term Effects of Breastfeeding. A Systematic Review. Geneva, World Health Organisation, 2013.

17 Weng SF, Redsell SA, Swift JA, Yang M, Glazebrook CP: Systematic review and metaanalyses of risk factors for childhood over- weight identifiable during infancy. Arch Dis Child 2012;97:1019-1026.

18 Yan J, Liu L, Zhu Y, Huang G, Wang PP: The association between breastfeeding and childhood obesity: a meta-analysis. BMC Public Health 2014;14:1267.

19 Koletzko B, Broekaert I, Demmelmair H, Franke J, Hannibal I, Oberle D, et al: Protein intake in the first year of life: a risk factor for later obesity? The E.U. childhood obesity project. Adv Exp Med Biol 2005;569:6979.

20 Koletzko B, Demmelmair H, Grote V, Prell C, Weber M: High protein intake in young children and increased weight gain and obesity risk. Am J Clin Nutr 2016;103:303304.

21 Heinig MJ, Nommsen LA, Peerson JM, Lonnerdal B, Dewey KG: Energy and protein intakes of breast-fed and formula-fed infants during the first year of life and their association with growth velocity: the DARLING study. Am J Clin Nutr 1993;58:152-161.

-22 Fleddermann M, Demmelmair H, Koletzko B: Energetic efficiency of infant formulae: a review. Ann Nutr Metab 2014;64:276-283.

23 Fleddermann M, Demmelmair H, Grote V, Nikolic T, Trisic B, Koletzko B: Infant formula composition affects energetic efficiency for growth: the BeMIM study, a randomized controlled trial. Clin Nutr 2014;33:588595.

24 Alexy U, Kersting M, Sichert-Hellert W, Manz F, Schoch G: Macronutrient intake of 3- to 36-month-old German infants and children: results of the DONALD study. Dortmund nutritional and anthropometric longitudinally designed study. Ann Nutr Metab 1999;43:14-22. 
25 Koletzko B, von Kries R, Monasterolo RC, Subias JE, Scaglioni S, Giovannini M, et al: Infant feeding and later obesity risk. Adv Exp Med Biol 2009;646:15-29.

-26 Koletzko B, von Kries R, Closa R, Escribano J, Scaglioni S, Giovannini M, et al: Lower protein in infant formula is associated with lower weight up to age 2 y: a randomized clinical trial. Am J Clin Nutr 2009;89:1836-1845.

27 Socha P, Grote V, Gruszfeld D, Janas R, Demmelmair H, Closa-Monasterolo R, et al: Milk protein intake, the metabolic-endocrine response, and growth in infancy: data from a randomized clinical trial. Am J Clin Nutr 2011;94(6 suppl):1776S-1784S.

-28 Kirchberg FF, Harder U, Weber M, Grote V, Demmelmair H, Peissner W, et al: Dietary protein intake affects amino acid and acylcarnitine metabolism in infants aged 6 months. J Clin Endocrinol Metab 2015;100:149-158.

29 Rzehak P, Grote V, Lattka E, Weber M, Gruszfeld D, Socha P, et al: Associations of IGF-1 gene variants and milk protein intake with IGF-I concentrations in infants at age 6 months - results from a randomized clinical trial. Growth Horm IGF Res 2013;23:149158.

-30 Weber M, Grote V, Closa-Monasterolo R, Escribano J, Langhendries JP, Dain E, et al: Lower protein content in infant formula reduces BMI and obesity risk at school age: follow-up of a randomized trial. Am J Clin Nutr 2014; 99:1041-1051.

31 Prell C, Koletzko B: Breastfeeding and complementary feeding. Dtsch Arztebl Int 2016; 113:435-444.
32 European-Commission. Commission Delegated Regulation (EU) 2016/127 of 25 September 2015 supplementing Regulation (EU) No 609/2013 of the European Parliament and of the Council as regards the specific compositional and information requirements for infant formula and follow-on formula and as regards requirements on information relating to infant and young child feeding. Official J Eur Union 2016:L 25/1.

33 European-Food-Safety-Authority-(EFSA): Scientific opinion on the safety and suitability for use by infants of follow-on formulae with a protein content of at least $1.6 \mathrm{~g} / 100 \mathrm{kcal}$. EFSA J 2017;15:4781.

34 Codex-Alimentarius-Commission: Report of the Thirty-Eight Session of the Codex Committee on Nutriton and Foods for Special Dietary Uses. Hamburg, Codex Alimentarius, Food and Agriculture Organisation of the United Nations, 2017.

35 Patro-Golab B, Zalewski BM, Kouwenhoven SM, Karas J, Koletzko B, Bernard van Goudoever J, et al: Protein concentration in milk formula, growth, and later risk of obesity: a systematic review. J Nutr 2016;146:551-564.

36 de Waard M, Brands B, Kouwenhoven SM, Lerma JC, Crespo-Escobar P, Koletzko B, et al: Optimal nutrition in lactating women and its effect on later health of offspring: a systematic review of current evidence and recommendations (Early Nutrition Project). Crit Rev Food Sci Nutr 2016, Epub ahead of print.
37 Patro-Gołąb B, Zalewski BM, Kołodziej M, Kouwenhoven S, Poston L, Godfrey KM, et al: Nutritional interventions or exposures in infants and children aged up to 3 years and their effects on subsequent risk of overweight, obesity and body fat: a systematic review of systematic reviews. Obes Rev 2016;17:12451257.

38 Flynn AC, Dalrymple K, Barr S, Poston L, Goff LM, Rogozinska E, et al: Dietary interventions in overweight and obese pregnant women: a systematic review of the content, delivery, and outcomes of randomized controlled trials. Nutr Rev 2016;74:312-328.

39 Bravi F, Wiens F, Decarli A, Dal Pont A, Agostoni C, Ferraroni M: Impact of maternal nutrition on breast-milk composition: a systematic review. Am J Clin Nutr 2016;104: 646-662.

40 Ong KK, Kennedy K, Castaneda-Gutierrez E, Forsyth S, Godfrey KM, Koletzko B, et al: Postnatal growth in preterm infants and later health outcomes: a systematic review. Acta Paediatr 2015;104:974-986.

41 Koletzko B, Boey CC, Campoy C, Carlson SE, Chang N, Guillermo-Tuazon MA, et al: Current information and Asian perspectives on long-chain polyunsaturated fatty acids in pregnancy, lactation, and infancy: systematic review and practice recommendations from an early nutrition academy workshop. Ann Nutr Metab 2014;65:49-80.

42 Patro B, Liber A, Zalewski B, Poston L, Szajewska H, Koletzko B: Maternal and paternal body mass index and offspring obesity: a systematic review. Ann Nutr Metab 2013;63:32-41. 